\title{
Fabrication of a Chitosan-Iron Oxide Nanocomposite for Electrochemical Detection of Trace Cadmium in Orchard Soil in the Loess Plateau
}

Qi Zhang ${ }^{1,2}$, Yan'an Tong ${ }^{1,2^{*}}$, Lili Yang ${ }^{1,2}$, Gaoyuan Liu ${ }^{1,2}$, Lianyou Liang ${ }^{1,2}$, Wenshe Han ${ }^{1,2}$ and Ming Zhang ${ }^{3}$

${ }^{1}$ College of Natural Resources and Environment, Northwest A \& F University, Yangling, Shaanxi, 712100 , China

${ }^{2}$ Key Laboratory of Plant Nutrition and the Agri-environment in Northwest China, Ministry of Agriculture, Shaanxi 712100, China

${ }^{3}$ College of Chemistry and Material Science, Sichuan University, 610064, China

*E-mail: shaanxizhangqi@163.com

doi: $10.20964 / 2017.11 .62$

Received: 25 July 2017 / Accepted: 10 September 2017 / Published: 12 October 2017

In this work, a chitosan-iron oxide nanocomposite (CHIT-IO) film was deposited onto fluorine tin oxide (FTO) to yield an electrochemical sensor to detect trace level cadmium. UV-visible spectroscopy and Fourier transform infrared spectroscopy (FTIR) were used to measure the iron oxide nanoparticles (IONPs) prepared via a co-precipitation technique. The increased electron transportation rate and remarkable electrochemical behaviour were confirmed for the synthesized electrode. Under optimum conditions, the stripping peak currents were linearly related to the concentration of the $\mathrm{Cd}(\mathrm{II})$ $(1.0-100.0 \mu \mathrm{g} / \mathrm{L}$ ), and a limit of detection (LOD) of $0.15 \mu \mathrm{g} / \mathrm{L}$ was obtained. The proposed electrode was then used for $\mathrm{Cd}(\mathrm{II})$ detection in soil extracts, and the desirable results are provided herein. The results indicate the proposed electrochemical determination method shows a comparable performance compared with that of the ICP-MS method.

Keywords: Electrochemical sensor; Chitosan; Iron oxide; Fluorine tin oxide; Cadmium; Soil

\section{$\underline{\text { FULL TEXT }}$}

(C) 2017 The Authors. Published by ESG (www.electrochemsci.org). This article is an open access article distributed under the terms and conditions of the Creative Commons Attribution license (http://creativecommons.org/licenses/by/4.0/). 